\title{
Forelimbs of the theropod dinosaur Dilophosaurus wetherilli: Range of motion, influence of paleopathology and soft tissues, and description of a distal carpal bone
}

\author{
Philip J. Senter and Corwin Sullivan
}

\begin{abstract}
Forelimb bones of the Early Jurassic theropod Dilophosaurus wetherilli were manually manipulated to determine the range of motion (ROM) of each forelimb joint and to test functional hypotheses of forelimb use. Using bony articular surface margins to delimit ROM, the humerus can be retracted to a position subparallel to the scapular blade, protracted no further than a subvertical position, and elevated only $65^{\circ}$. The elbow cannot be flexed beyond a right angle to the humerus. Supination and pronation are prevented by lack of rolling radio-ulnar joints, and the palms face medially. The distal carpal block of Dilophosaurus, described here for the first time, is relatively flat and lacks a proximal trochlea, suggesting limited wrist mobility. The fingers diverge during flexion and are extremely hyperextensible. Experiments on American alligator cadavers show that ROM exhibits limited intraspecific variation and is greater in the fullyfleshed elbow than skeletal manipulation suggests. Here, we apply these findings and those of previous studies on extant archosaurs to reconstruct ROM in the forelimbs of live Dilophosaurus by adjusting the results of the bare-bones manipulations to account for the known influence of soft tissues. We also discuss the effects of skeletal deformities on inferred ROM in Dilophosaurus. Forelimb morphology and ROM are consistent with two-handed prehension, clutching objects to the chest, manually hooking objects, and seizing prey beneath the predator's chest or the base of its neck (but no further forward). Limited shoulder mobility suggests that the mouth, not the hands, made first contact with prey.
\end{abstract}

Philip J. Senter. Department of Biological Sciences, Fayetteville State University, 1200 Murchison Road, Fayetteville, North Carolina 28301, USA. psenter@uncfsu.edu

Corwin Sullivan. Department of Biological Sciences, University of Alberta, Edmonton, Alberta T6G 2E9, Canada; and Philip J. Currie Dinosaur Museum, Wembley, Alberta TOH 3S0, Canada.

corwin1@ualberta.ca.

Senter, Philip J. and Sullivan, Corwin. 2019. Forelimbs of the theropod dinosaur Dilophosaurus wetherilli: Range of motion, influence of paleopathology and soft tissues, and description of a distal carpal bone. Palaeontologia Electronica 22.2.30A 1-19. https://doi.org/ $10.26879 / 900$

palaeo-electronica.org/content/2019/2559-dilophosaurus-forelimbs

Copyright: June 2019 Paleontological Society.

This is an open access article distributed under the terms of Attribution-NonCommercial-ShareAlike 4.0 International (CC BY-NC-SA 4.0 ), which permits users to copy and redistribute the material in any medium or format, provided it is not used for commercial purposes and the original author and source are credited, with indications if any changes are made.

creativecommons.org/licenses/by-nc-sa/4.0/ 
Keywords: Dinosauria; Theropoda; Dilophosaurus; range of motion; functional morphology; Alligator mississippiensis

Submission: 15 June 2018. Acceptance: 1 May 2019.

\section{INTRODUCTION}

Dilophosaurus wetherilli is a basal theropod dinosaur (Smith et al., 2007) from the Lower Jurassic Kayenta Formation of Arizona (Welles, 1984). Welles (1954) originally described this species under the name Megalosaurus wetherilli, but later erected the genus name Dilophosaurus for it following the discovery of a second specimen and examination of a wide range of theropod material (Welles, 1970). Most of the forelimb elements of the holotype specimen of $D$. wetherilli (UCMP 37302) are present and disarticulated, allowing the range of motion (ROM) in the forelimbs to be inferred based on arthrological features. Welles (1984) drew some limited inferences regarding ROM in the forelimbs of $D$. wetherilli, but did not investigate this issue comprehensively. In particular, Welles (1984) illustrated the left hand of the holotype of $D$. wetherilli in postures that he considered to represent full flexion and full hyperextension, and he gave ROM estimates for some joints within the manus as well as for the shoulder and elbow. However, he did not describe the method used to produce his estimates or illustrate the inferred ROM for the shoulder and elbow. Furthermore, the holotype exhibits paleopathological asymmetry between the left and right forelimbs (Senter and Juengst, 2016) (Figures 1, 2), and the influence of this condition on ROM has not been explored before now. Here, we seek to fill gaps in published knowledge of the forelimbs of $D$. wetherilli by providing new estimates of the ROM in the joints of the holotype, describing the methods used to determine these estimates, describing the influence of paleopathology on the ROM, and describing a previously-undescribed distal carpal bone.

ROM in the forelimb or some part thereof has been studied in several other theropod species, including the basal (non-averostran) theropods Herrerasaurus ischigualastensis (Sereno, 1993), Coelophysis bauri (Carpenter, 2002), and Megapnosaurus rhodesiensis (Galton, 1971); the abelisaurid Carnotaurus sastrei (Senter and Parrish, 2006); the allosauroids Allosaurus fragilis (Carpenter, 2002) and Acrocanthosaurus atokensis (Senter and Robins, 2005); the megaraptorid Australovenator wintonensis (White et al., 2015); the tyranno- saurid Tyrannosaurus rex (Carpenter, 2002); the ornithomimosaurs Deinocheirus mirificus (Osmólska and Roniewicz, 1969), Harpymimus okladnikovi (Kobayashi and Barsbold, 2005), Gallimimus bullatus (Osmólska et al., 1972), Gallimimus sp. (Kobayashi and Barsbold, 2005), and Struthiomimus altus (Nicholls and Russell, 1985); the alvarezsaurid Mononykus olecranus (Senter, 2005); the oviraptorosaur Chirostenotes pergracilis (Senter and Parrish, 2005); and the dromaeosaurids Bambiraptor feinbergi (Senter, 2006b) and Deinonychus antirrhopus (Gishlick, 2001; Carpenter, 2002; Senter, 2006b). In each case, the researchers used the edges of the articular surfaces of the bones to place limits on the inferred ROM but had little available empirical basis for estimating how the presence of soft tissues might have influenced joint mobility in the living animal.

Recent studies of extant archosaurs have begun to clarify the influence of soft tissues on ROM in archosaur limbs, which were probably broadly characterized by substantial amounts of articular cartilage capping the articular surfaces of the individual bones (Fujiwara et al., 2010; Holliday et al., 2010; Tsai and Holliday, 2015). Hutson and Hutson (2012, 2013, 2014, 2015a, 2015b) recorded the ROM in various joints of intact ostrich (Struthio camelus) and American alligator (Alligator mississippiensis) forelimbs, then skinned and defleshed the specimens and recorded the ROM in the same joints according to the osteological criteria previously used in ROM studies on non-avian theropods. White et al. (2016) performed a similar study with an emu (Dromaius novaehollandiae) foot. Fujiwara et al. (2010) studied the influence of articular cartilage on ROM in the alligator elbow. In the present paper, we present some novel results on the range of elbow joint motion in intact $A$. mississippiensis cadavers that supplement the findings of previous studies by quantifying intraspecific variation and allowing evaluation of the influence of specimen size. Taken together, these neontological data provide useful information on how ROM results obtained for extinct archosaur forelimbs by manipulation of fossilized bones should be corrected to produce estimates applicable to the live animal. We apply such correction factors to new osteological ROM estimates for the forelimbs of $D$. 

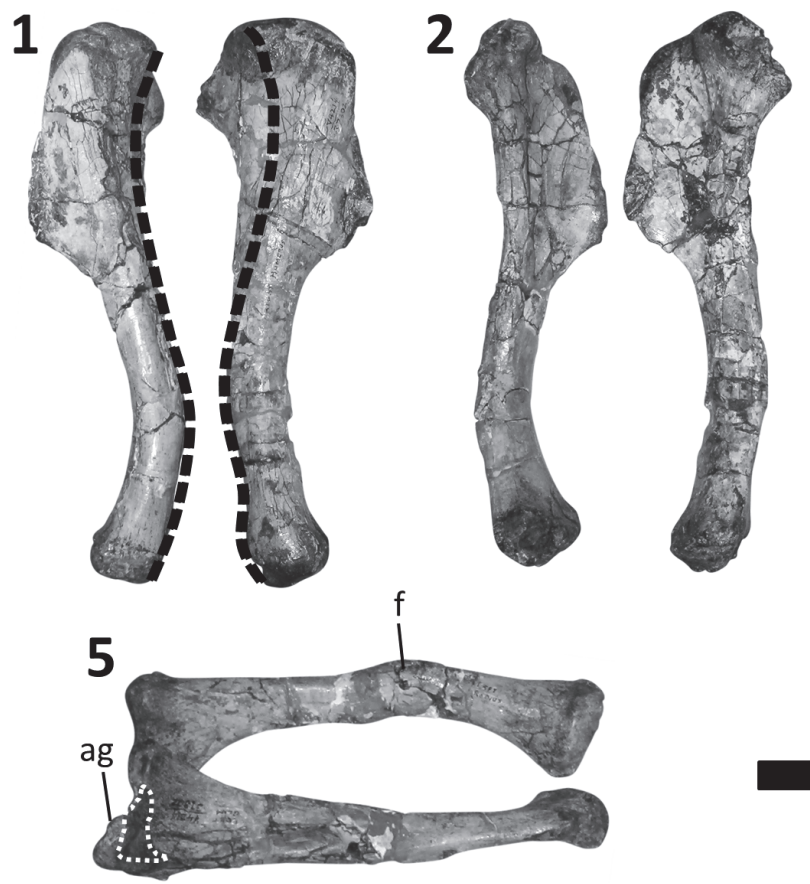

3
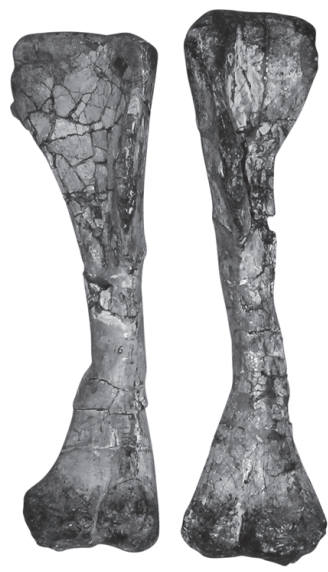

4

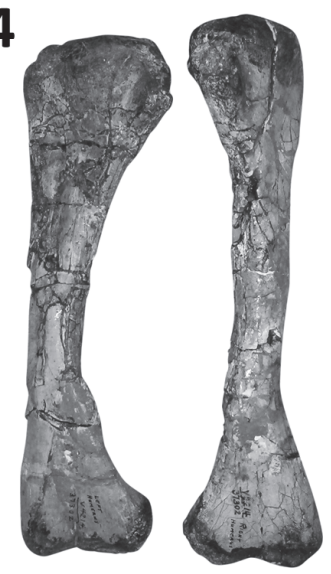

6

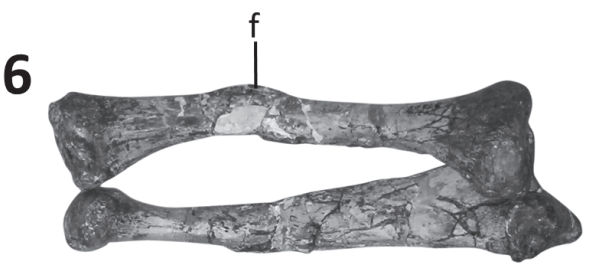

bt
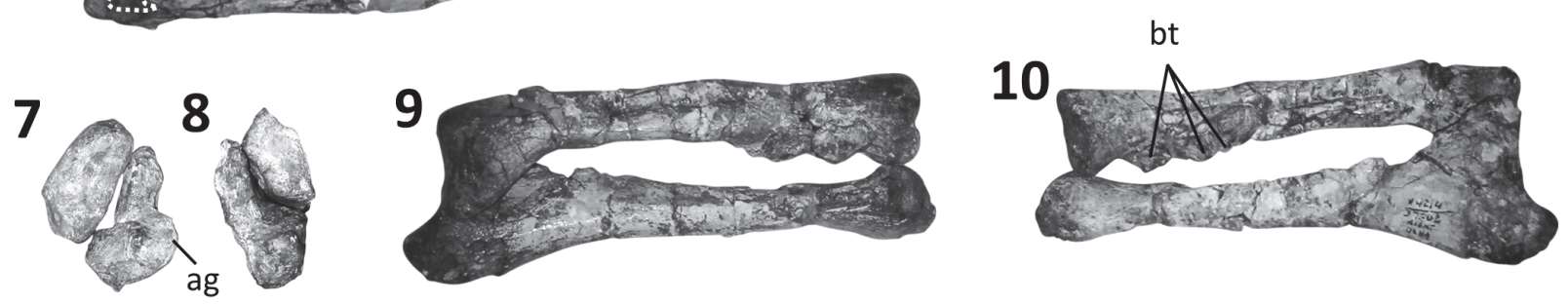

FIGURE 1. Humerus, radius, and ulna of the holotype of Dilophosaurus wetherilli. 1-4, left (on left) and right (on right) humerus in lateral (1), medial (2), anterior (3), and posterior (4) views, with views standardized according to the orientation of the distal condyles. 5-7, left radius and ulna in medial (5), lateral (6), and proximal (7) views. 8-10, right radius and ulna in proximal (8), lateral (9), and medial (10) views. Broken black lines in 1 indicate the midlines of the posterior (retractor) surface of the left humerus and the homologous surface of the right humerus, showing the strong degree of abnormal torsion of the diaphysis of the right humerus. Broken white line in $\mathbf{5}$ delineates the edge of a pathological cavitation. Abbreviations: ag, abnormal growth on ulna; bt, bony tumors; f, fracture of radius. Scale bar equals $50 \mathrm{~mm}$.

wetherilli, in order to more accurately understand the kinematic limitations this theropod would have faced as a living organism.

Because an animal will not do what it cannot do, behavioral hypotheses are falsified if they require a ROM exceeding that available to the animal in question. Here, we use our inferred ROM limits for the forelimbs of $D$. wetherilli to test a previously-published (Senter, 2006b) set of functional/ behavioral hypotheses for forelimb use in this animal, so as to elucidate its anatomical capabilities and contribute to behavioral reconstruction.

\section{Institutional Abbreviations}

TMM, Texas Memorial Museum, Austin, Texas, USA.; UCMP, University of California Museum of Paleontology, Berkeley, California, USA.

\section{MATERIAL AND METHODS}

\section{Dilophosaurus wetherilli}

The holotype specimen of Dilophosaurus wetherilli (UCMP 37302) includes the scapulae, coracoids, humeri, radii, and ulnae from both sides. The left hand is missing only the carpals, the distal half of phalanx II-1, and all but the proximalmost portion of phalanx I-2. The specimen also includes a partial right hand, comprising metacarpals I - III, phalanges $\mathrm{I}-1, \mathrm{II}-3$, and $\mathrm{III}-1$, and a previouslyundescribed distal carpal element (Figure 3).

Initially, ROMs for the various forelimb joints were estimated using the "bare-bones" method applied in the previous studies of theropod forelimbs cited above, in which the edges of the preserved articular surfaces were presumed to define 
1

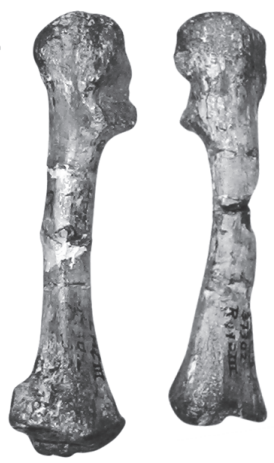

4
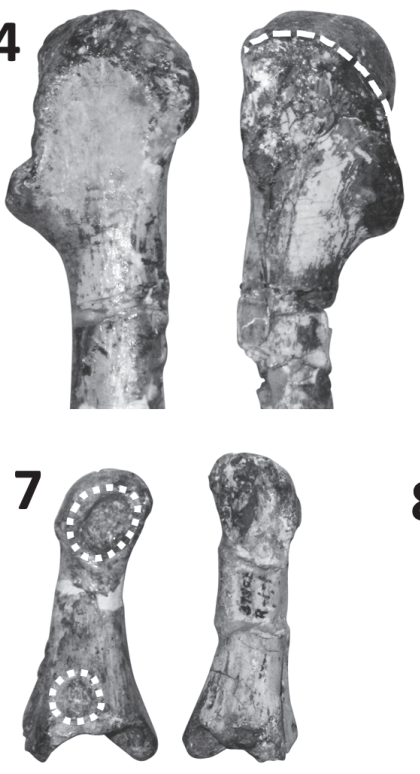

11

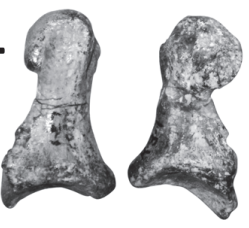

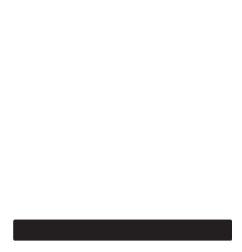

2

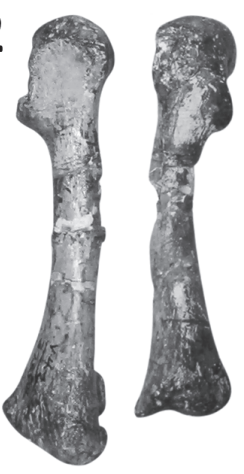

5

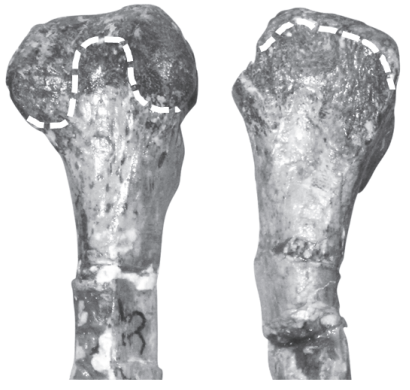

3

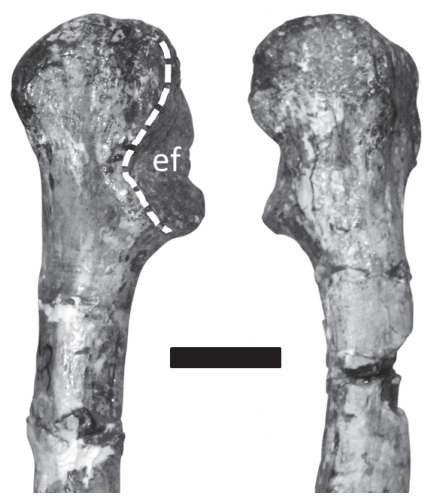

6

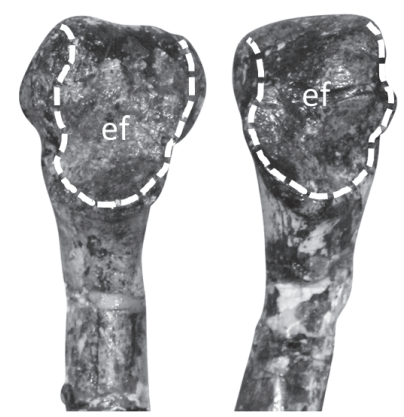

9

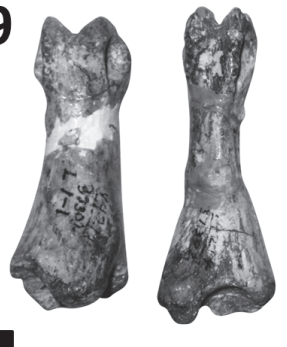

13

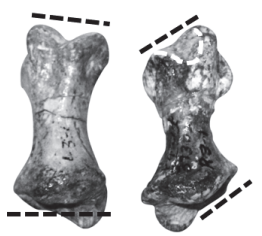

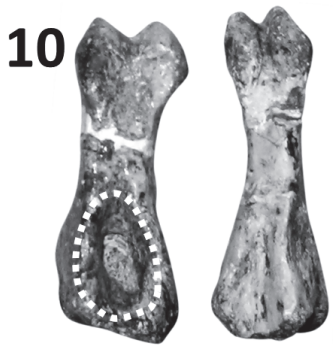

14

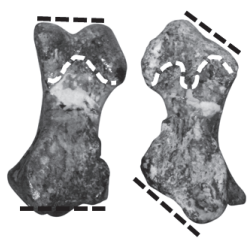

FIGURE 2. Asymmetry between bones of the left and right hands. In each panel of the figure, the bone from the left hand is on the left, and the bone from the right hand is on the right. 1-2, metacarpal III in posterior (1) and anterior (pollical) (2) views. 3-6, distal end of metacarpal III in posterior (3), anterior (4), flexor (palmar) (5) and extensor (lateral) (6) views. 7-10, manual phalanx I-1 in posterior (7), anterior (8), flexor (9) and extensor (10) views. 11-14, manual phalanx III-1 in posterior (11), anterior (12), flexor (13) and extensor (14) views. Broken white lines in 3-6 and 12-14 indicate edges of articular surfaces. Broken white lines in 7 and 10 indicate pathological pitting. Broken black lines in 13 and 14 indicate orientations of homologous surfaces of the phalanges of the two hands. Abbreviation: ef, extensor fossa. Scale bar equals $50 \mathrm{~mm}$ in 1-2 and 7-14. Scale bar equals $10 \mathrm{~mm}$ in 3-6.

the limits of motion (Figure 4). This method involves the assumption that at a given joint the articular surface of the distal bone will not pass beyond the edge of the articular surface of the proximal bone. Subsequently, data from extant archosaurs on the relationship between barebones ROM estimates and experimental ROM measurements on cadavers with intact soft tissues were used as a basis for inferring how ROM for joints in the forelimb of a living Dilophosaurus may have differed from our bare-bones values.

To implement the bare-bones method of ROM estimation, the edges of the articular surfaces are identified as precisely as possible on the basis of 


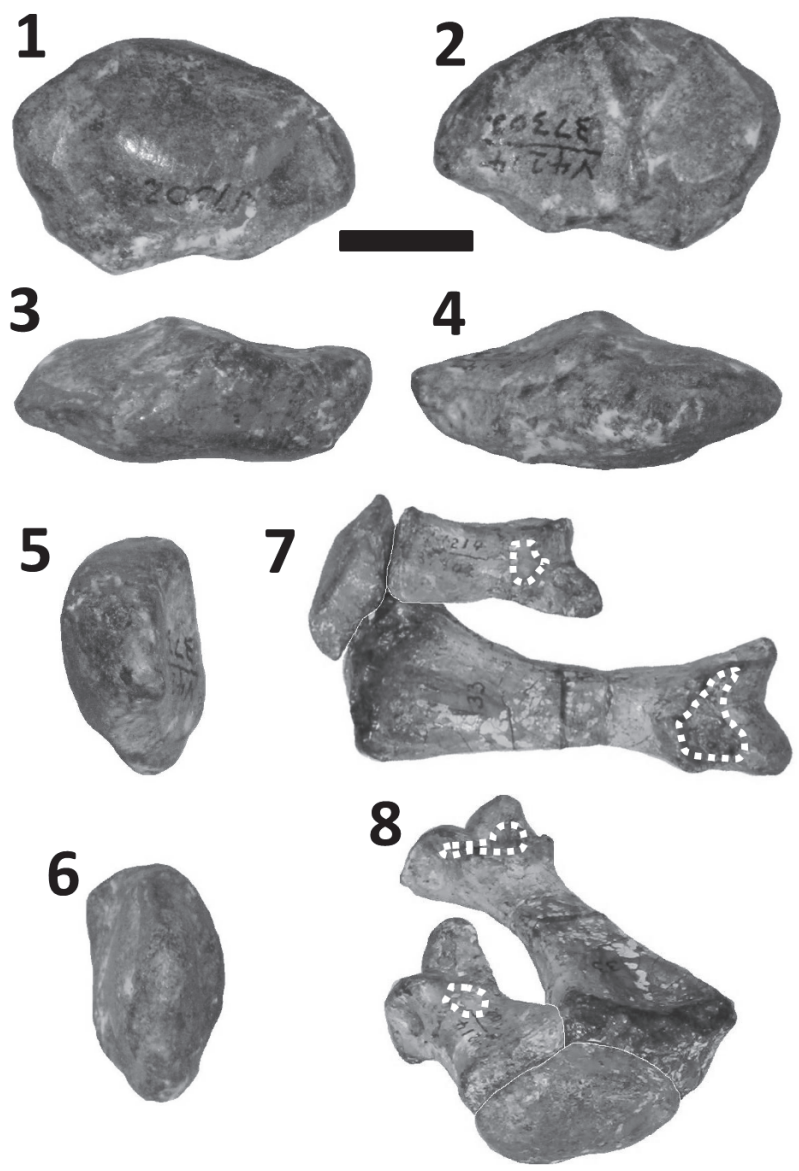

FIGURE 3. Distal carpal element (distal carpals $1+2$ ) of right hand of holotype of Dilophosaurus wetherilli. 1, proximal view. 2, distal view. 3, extensor view. 4, flexor view. 5, posterior view. 6, anterior view. 7-8, distal carpal in articulation with the first and second metacarpals in extensor (7) and oblique proximo-extensor (8) views. Dotted white outlines indicate edges of extensor fossae. Scale bar equals $15 \mathrm{~mm} .7$ and 8 not to scale.

abrupt changes in texture and/or topology, which are more obvious in some cases than in others. Using the edges of articular surfaces as guides, skeletal elements were posed at the extremes of motion for photography in orthal views. Skeletal elements were supported from beneath as needed by sheets and blocks of foam rubber, wire test tube racks, and/or padded horizontal bars clamped to chemistry ring stands, and were fastened together as needed by plastic-coated wire twists. Photos of skeletal elements at the estimated extremes of motion were digitally superimposed, a line was drawn down the long axis of each element, and the ranges of motion were measured from the angles between the lines with a protractor. The long axis of the humerus in lateral view was considered to be a line connecting the center of the articular surface of the humeral head to the center of the lateral epicondyle. The long axis of the antebrachium in lateral view was considered to be a line parallel to the radius that intersected the center of rotation (as determined by manual manipulation of bones) of the antebrachium. The long axis of each ungual phalanx was considered to be perpendicular to a line connecting the tips of the dorsal and palmar lips of the phalanx's proximal articular surface.

To study the ROM of the shoulder joint, the scapula and coracoid were placed on a table as if the animal were lying on its contralateral side, with the medial surface of the distal half of the scapular blade parallel to the plane of the tabletop (which approximated the midsagittal plane of the animal), because articulated specimens show that in nonavian dinosaurs the scapula was lateral and not dorsal to the ribcage (Senter, 2006c; Senter and Robins, 2015). The long axis of the scapular blade was oriented at approximately $21^{\circ}$ from the edge of the table. This allowed the edge of the table to serve as a proxy for the animal's horizontal anteroposterior axis in photos taken in lateral view, in accordance with the recent finding that in theropods the long axis of the scapular blade was oriented at approximately $21^{\circ}$ above the animal's horizontal anteroposterior axis (Senter and Robins, 2015).

Manipulation of the shoulder joint revealed that the humerus of $D$. wetherilli does not fit precisely into the glenoid cavity. This is also the case in extant archosaurs, in which there is a cap of articular cartilage whose shape does not precisely match that of the underlying bony surface of the glenoid (Holliday et al., 2010). Using the logic of the extant phylogenetic bracket approach (Witmer, 1995), we infer that the same was the case in Dilophosaurus, accounting for the small gap that can be observed between the opposing bony articular surfaces of the humeral head and the glenoid cavity through the entire ROM. However, the glenoid cavity and the head of the humerus are welldefined, with clearly demarcated edges. This allowed the protocol used in previous studies (Senter, 2005, 2006b; Senter and Robins, 2005; Senter and Parrish, 2006) to be employed, as follows. The humerus was posed for maximum protraction with the anterior edge of the humeral head aligned with the coracoid lip of the glenoid cavity, and posed for maximum retraction with the posterior edge of the humeral head aligned with the scapular lip of the glenoid cavity. The humerus was posed for maximum elevation (abduction) with the lateral edge of the humeral head aligned with the 
1
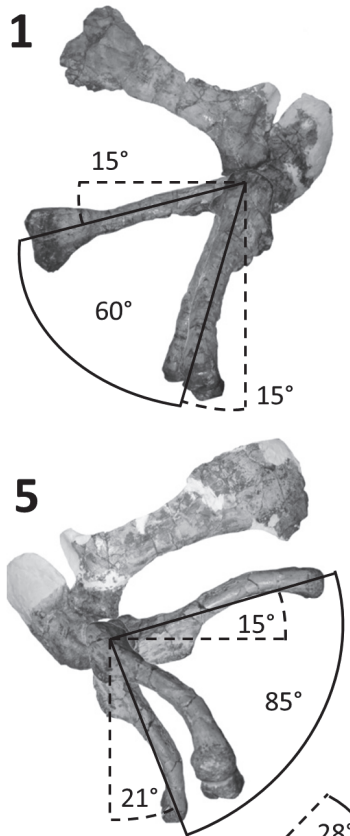

9
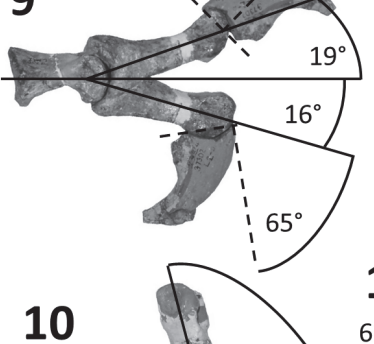

10

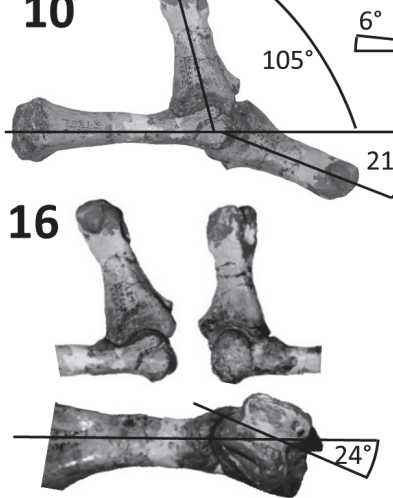

2

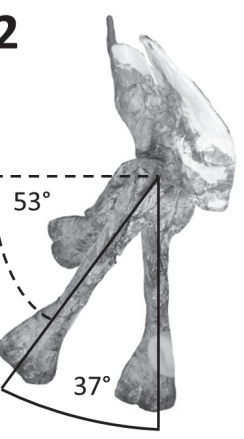

6

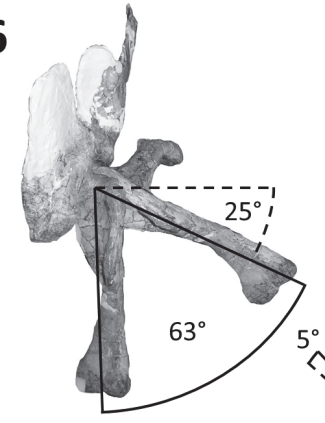

3
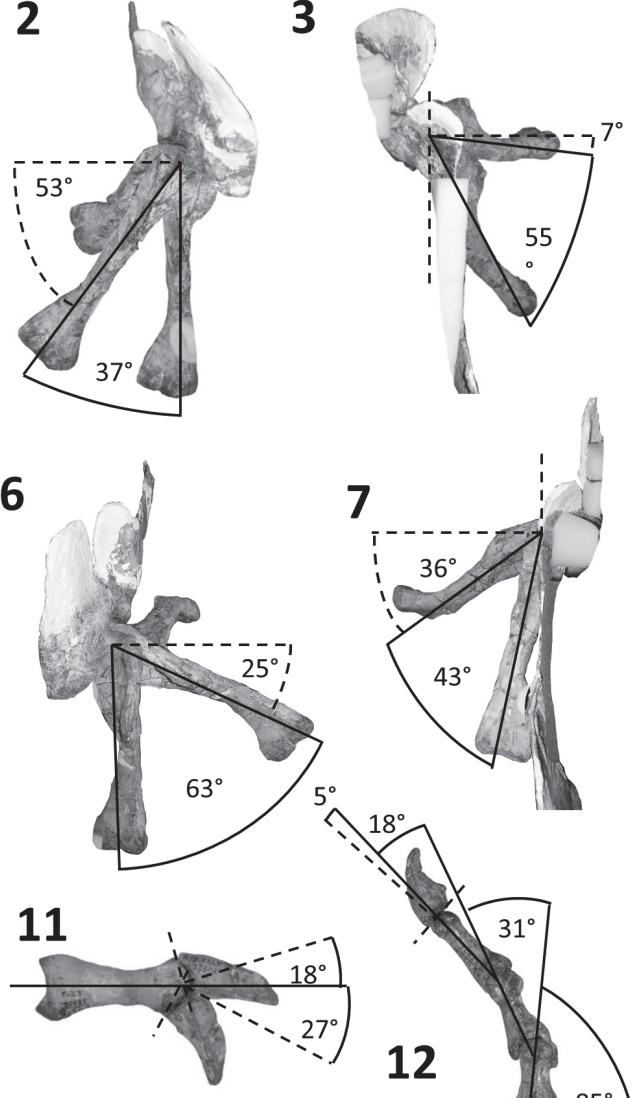

7

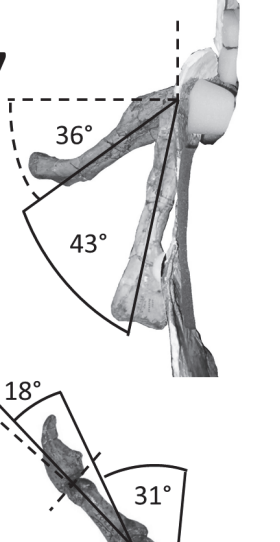

12

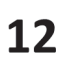

13
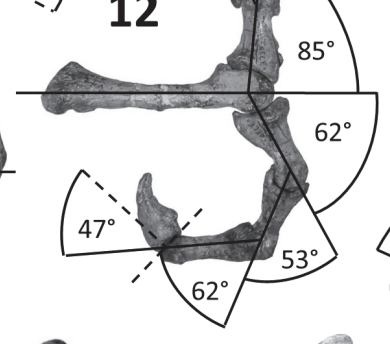

4
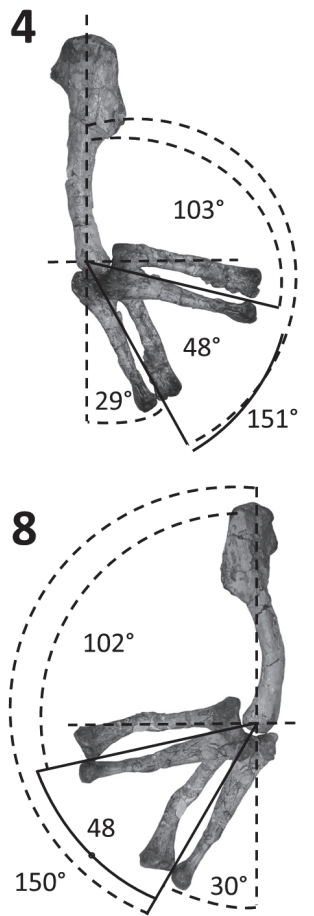

14
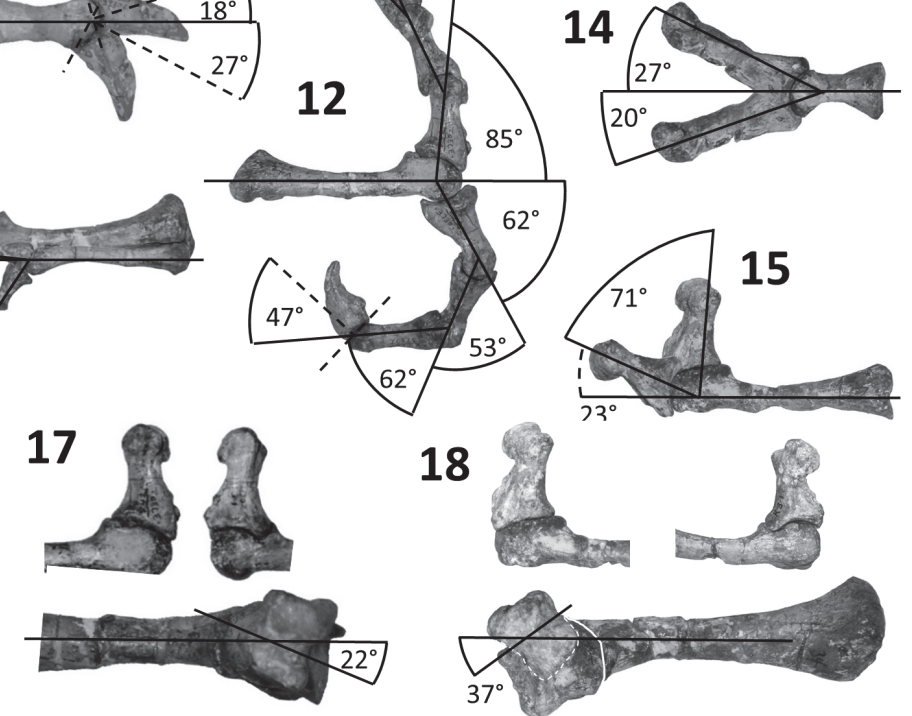

18

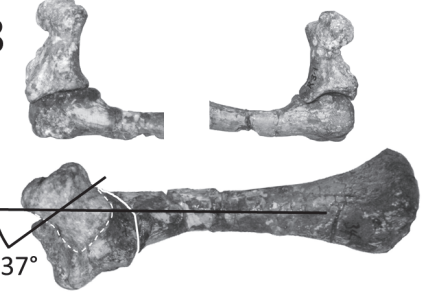

FIGURE 4. Range of motion in the forelimb of the holotype of Dilophosaurus wetherilli. 1-3. right shoulder in lateral (1), anterior (2), and dorsal (3) views. 4. right elbow in lateral view. 5-7. left shoulder in lateral (5), anterior (6), and dorsal (7) views. 8. left elbow in lateral view. 9. anterior view of right metacarpal I and phalanx I-1 of the holotype, with phalanx I-2 of UCMP 37303. 10. left metacarpal II and phalanx II-1 in anterior view. 11. left phalanges II-1 and II-2 in anterior view. 12. left digit III in anterior view. 13. left digit IV in posterior view. 14. right metacarpal I and phalanx I-1 in anterior view. 15. right metacarpal III and phalanx III-1 in anterior view. 16. left metacarpal II and phalanx II-1 in anterior (top left), posterior (top right), and extensor (bottom) views. 17. left metacarpal III and phalanx III-1 in anterior (top left), posterior (top right), and extensor (bottom) views. 18. right metacarpal III and phalanx III-1 in anterior (top left), posterior (top right), and extensor (bottom) views, with broken white outline indicating distal end of proximal phalanx, and solid white outline indicating proximal end of proximal phalanx. Note that the range of elevation measured in $\mathbf{2}$ and $\mathbf{6}$ is elevation by abduction, although the distal end of the humerus can be lifted higher during retraction (as shown by the retracted humerus in those panels of the figure). Note, too that the view of the elevated humerus obscures the view of the protracted humerus in $\mathbf{1}$ but not $\mathbf{5}$, which shows the influence of paleopathology in the misshapen right humerus, as does the long-axis rotation of the right humerus during retraction as shown in 1. 
lateral edge of the glenoid cavity at the joint between the scapula and coracoid. The humeral head is more extensive and bulbous on the posterior side of the humerus than on the anterior side, allowing a greater degree of retraction than protraction (Figure 4).

To study the elbow joint, the humerus, radius and ulna were placed in articulation and positioned so that the lateral epicondyle of the humerus faced the camera. Flexion and extension of the radius and ulna therefore occurred in a plane parallel to the surface of the table. A small gap is present between the two antebrachial bones and the humerus throughout the ROM of the elbow. Again, this probably reflects the absence of articular cartilage (Holliday et al., 2010), a substantial amount of which is present in the elbows of extant archosaurs (Fujiwara et al., 2010). However, the surfaces that participate in the elbow joint are well-defined on the radius and ulna, and on the right humerus, allowing the use of the protocol adopted in previous studies (Senter, 2005, 2006b; Senter and Robins, 2005; Senter and Parrish, 2006). On the left humerus the edges of the articular surfaces are not sharply defined, but the shapes of the surfaces sufficiently resemble those of the right humerus to allow replication of the protocol used for the right elbow. For maximum flexion, the bones were posed so that the proximal edge of the radial condyle on the anterior surface of the humerus was aligned with the edge of the radial head. For maximum extension, the bones were posed so that the proximal edge of the trochlear notch of the ulna was aligned with the proximal edge of the distal articular surface, situated on the posterior face of the humerus (Figure 4).

To study the ranges of flexion and extension at the manual joints, the bones of each finger were positioned with the anterior (pollical) surface facing the tabletop, so that the posterior surface (the surface facing away from the thumb) faced the camera. In the ROM photos for the left hand we used the right phalanx I-2 of UCMP 37303 , a similarlysized referred specimen of $D$. wetherilli, because only a fragment of the corresponding left phalanx was present in the holotype. Although this entailed combining bones from two different individuals and from opposite sides of the body, the degree of fit at the interphalangeal joint of the composite digit I appeared adequate to provide a reasonable barebones estimate of the ROM; the joint surfaces of both phalanges are symmetrical about the median plane of the proximal phalanx, preventing the introduction of error from anterior or posterior deviation of the ungual within its arc of motion, and the condyles and complementary cotyles closely match one another in shape, size, and orientation. Unfortunately, no similar replacement was available for the left phalanx II-1 of the holotype, which is also incomplete. To illustrate rotation about the long axes of some phalanges during flexion and/or hyperextension, the metacarpals and manual phalanges were fastened together with plastic-coated wire twists and photographed in the extremes of motion in various views in flexion and hyperextension (Figure 5). The bones of the hand exhibit snugly fitting and well-demarcated articular surfaces that usually terminate in bony stops in both directions, preventing further motion. The protocol used in previous studies (Senter, 2005, 2006a, b; Senter and Parrish, 2005; Senter and Robins, 2005), in which phalanges were posed at the limits defined by their articular surfaces, was followed here.

\section{Alligator mississippiensis}

P.S. manually manipulated the forelimb skeletons of six specimens of Alligator mississippiensis, to measure the "bare bones" range of elbow motion (Table 1). The humerus, radius, and ulna of each forelimb were posed with the elbow in maximum flexion and maximum extension, using the procedure described above for Dilophosaurus wetherilli (Figure 6.1). As in D. wetherilli, the bones of the elbow do not exhibit snug fit, due to the presence in life of substantial articular cartilages (Fujiwara et al., 2010; Holliday et al., 2010) (Figure 6.2). However, the edges of the articular surfaces of the humerus, radius, and ulna at the elbow are distinctly defined, allowing the same protocol that was used for $D$. wetherilli to be applied to the alligator. The length of each humerus was recorded as a proxy for overall size (Table 1), in order to investigate the possibility of a relationship between size and ROM. That investigation involved the use of the PEARSON function in Microsoft Excel 2016 to determine whether a correlation existed between humeral length and the range of elbow flexion.

C.S. measured the range of elbow motion in seven intact (including skin) cadavers of juvenile $A$. mississippiensis (Table 1). X-ray radiographs of each specimen were made with the elbow in maximum flexion (Figure 6.2) and maximum extension, using a Siemens radiographic apparatus. Humeral lengths could not be measured, because the specimens' forelimbs were kept intact and the humerus was not precisely in the radiographic plane when each image was taken. 

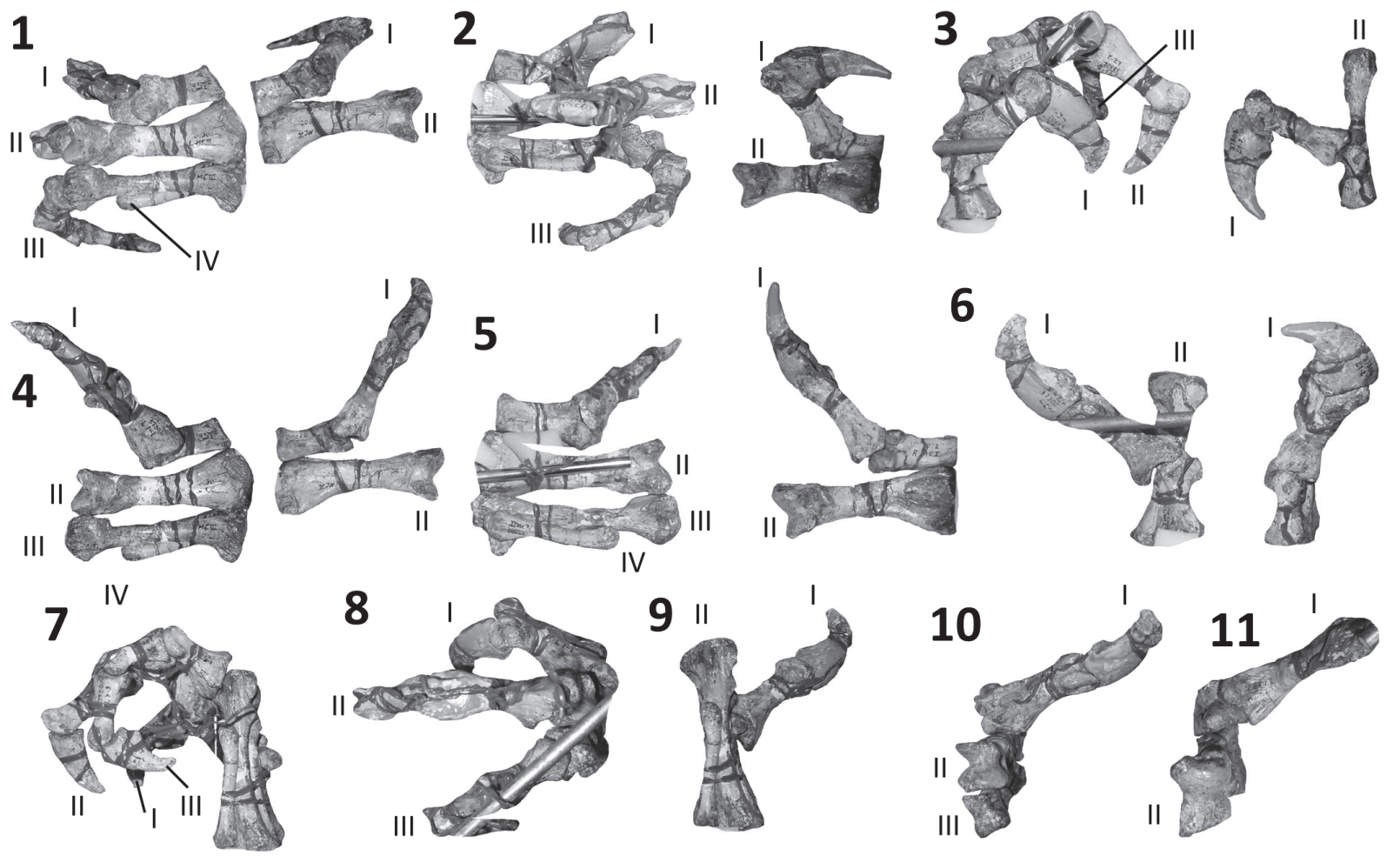

FIGURE 5. Bones of the left hand of the holotype of Dilophosaurus wetherilli in flexion (all bones except phalanx IV-1) and hyperextension (metacarpus and thumb only), and bones of the right hand (metacarpal I, metacarpal II, and thumb) in flexion and hyperextension. In 1-6, the bones of the left hand are on the left side, and the bones of the right hand are on the right side. 1-3, flexion in lateral (1), palmar (2), and anterior (3) views. 4-6, hyperextension in lateral (4), palmar (5), and anterior (6) views. 7-8, flexion of left hand in posterior view (7) and from the perspective of a distal view of the metacarpus (8). 9-10, hyperextension of left thumb in posterior view (9) and from the perspective of a distal view of the metacarpus (10). 11, flexion of phalanx I-1 of the right hand, from the perspective of a distal view of the metacarpus. Abbreviations: I - III, number of digit or metacarpal.

\section{RESULTS}

\section{Distal Carpal Element of Dilophosaurus wetherilli}

The Dilophosaurus wetherilli holotype includes a flattened, elliptical carpal element (Figure 3) with a proximodistal thickness of $15 \mathrm{~mm}$, a transverse diameter of $32 \mathrm{~mm}$, and a dorso-palmar diameter of $25 \mathrm{~mm}$. This element is therefore too large by a considerable margin to correspond to any of the carpals that Welles (1984) described: the radiale $(21 \times 4 \times 11 \mathrm{~mm})$, the ulnare $(29 \times 9 \times$ $15 \mathrm{~mm})$, and the intermedium $(21 \times 7 \times 21 \mathrm{~mm})$. It fits perfectly over the proximal ends of the right metacarpals I and II of the holotype, and a facet is present for each of these two metacarpals on its distal surface. It can therefore be identified as fused distal carpals $1+2$ (Botelho et al., 2014). The bone's proximal surface is only slightly convex (both transversely and in the dorso-palmar dimension) and lacks a trochlea. It therefore resembles the distal carpal block (distal carpals $1+2$ ) of coelophysoids (Raath, 1969; Colbert, 1989) and not the distal carpal block of tetanuran theropods, which exhibits a "semilunate" morphology defined by a more distinctly convex proximal surface that forms a prominent trochlea (Botelho et al., 2014).

\section{Range of Motion: Alligator mississippiensis Elbow}

For the bare-bones manipulations, maximum elbow flexion ranged from $74^{\circ}$ to $89^{\circ}$, with a mean of $85.2^{\circ}$ (Table 1 ). Maximum elbow extension ranged from $144^{\circ}$ to $169^{\circ}$, with a mean of $155.2^{\circ}$ (Table 1). Within our sample, in which humeral lengths ranged from $75 \mathrm{~mm}-230 \mathrm{~mm}$ (Table 1), humeral length did not correlate with range of elbow flexion $(R=-0.59959)$ or extension $=-0.30174$ ).

For the intact specimens, maximum elbow flexion ranged from $23^{\circ}$ to $39^{\circ}$, with a mean of $30.2^{\circ}$ (Table 1). Measurements for elbow extension 
TABLE 1. Elbow flexion in American alligators (Alligator mississippiensis) as found by manual manipulation.

\begin{tabular}{|c|c|c|c|c|}
\hline $\begin{array}{l}\text { Accession/ } \\
\text { specimen } \\
\text { number }\end{array}$ & $\begin{array}{l}\text { Side of } \\
\text { body }\end{array}$ & $\begin{array}{l}\text { Humeral } \\
\text { length }\end{array}$ & $\begin{array}{l}\text { Maximum } \\
\text { flexion }\end{array}$ & $\begin{array}{l}\text { Maximum } \\
\text { extension }\end{array}$ \\
\hline \multicolumn{5}{|c|}{ Bare-bones specimens } \\
\hline TMM 2433 & left & $75 \mathrm{~mm}$ & $89^{\circ}$ & $159^{\circ}$ \\
\hline TMM 2433 & right & $75 \mathrm{~mm}$ & $88^{\circ}$ & $162^{\circ}$ \\
\hline TMM 7363 & left & $95 \mathrm{~mm}$ & $76^{\circ}$ & $155^{\circ}$ \\
\hline TMM 7363 & right & $95 \mathrm{~mm}$ & $83^{\circ}$ & $169^{\circ}$ \\
\hline TMM 3004 & left & $110 \mathrm{~mm}$ & $89^{\circ}$ & $150^{\circ}$ \\
\hline TMM 3004 & right & $111 \mathrm{~mm}$ & $88^{\circ}$ & $144^{\circ}$ \\
\hline TMM 7487 & right & $113 \mathrm{~mm}$ & $74^{\circ}$ & $147^{\circ}$ \\
\hline TMM 7489 & left & $114 \mathrm{~mm}$ & $91^{\circ}$ & $161^{\circ}$ \\
\hline TMM 7489 & right & $113 \mathrm{~mm}$ & $92^{\circ}$ & $157^{\circ}$ \\
\hline TMM 4135 & left & $230 \mathrm{~mm}$ & $82^{\circ}$ & $148^{\circ}$ \\
\hline Mean & & & $\begin{array}{l}\text { left: } 85.4^{\circ} \\
\text { right: } 85.0^{\circ} \\
\text { all: } 85.2^{\circ}\end{array}$ & $\begin{array}{l}\text { left: } 154.6^{\circ} \\
\text { right: } 155.8^{\circ} \\
\text { all: } 155.2^{\circ}\end{array}$ \\
\hline \multicolumn{5}{|c|}{ Intact specimens (fully-fleshed, including skin) } \\
\hline Cadaver 1 & left & & $23^{\circ}$ & \\
\hline Cadaver 2 & left & & $39^{\circ}$ & \\
\hline Cadaver 3 & left & & $32^{\circ}$ & \\
\hline Cadaver 4 & left & & $23^{\circ}$ & \\
\hline Cadaver 5 & left & & $31^{\circ}$ & \\
\hline Cadaver 6 & left & & $33^{\circ}$ & \\
\hline Mean & & & $30.2^{\circ}$ & \\
\hline
\end{tabular}

in intact specimens were not recorded, because the radiographs revealed that during elbow extension each humerus had rotated about its long axis in such a way that it was not being imaged in the same plane as the humeri from the skeletal specimens. Elbow extension in the intact specimens therefore could not be directly compared with cor-

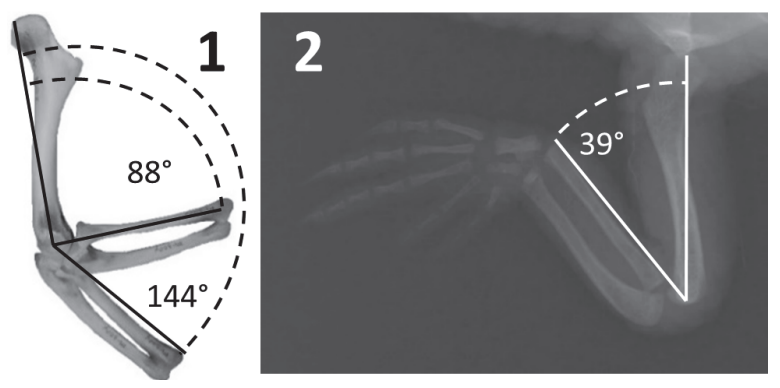

FIGURE 6. Range of motion at the elbow in specimens of Alligator mississippiensis. 1, a skeletal specimen: right forelimb of TMM 3004. 2, an intact specimen: left forelimb of Cadaver 2, showing that the humeral orientation relative to the viewer during elbow flexion matches that of the skeletal specimen. responding measurements in the skeletal specimens.

The differences in maximum elbow flexion and extension among specimens show that intraspecific variation exists in these values. The fact that the amount of flexion possible in intact specimens exceeded that possible in skeletal specimens by some $55^{\circ}$ shows that the bare-bones method tends to considerably underestimate the amount of flexion possible in a cadaver, and potentially also in the live animal. It is therefore plausible that this method might similarly underestimate elbow flexion in theropods and other extinct archosaurs.

\section{Range of Motion: Dilophosaurus wetherilli (Bare Bones)}

This section describes bare-bones ROM results. For adjustments that must be made to take into account the influence of soft tissues, see the following section.

The left humerus of the specimen can be retracted to a position subparallel with the long axis of the scapular blade and can be elevated up to 
$63^{\circ}$. Protraction is limited, allowing the humerus to approach but not achieve a vertical orientation (Figure 4). The diaphysis of the right humerus exhibits approximately $35^{\circ}$ of abnormal torsion in comparison to the left humerus (Senter and Juengst, 2016) (Figure 1.1). This deformity is accompanied by a change in shape of the diaphysis, affecting the angle between the diaphysis and the humeral head, such that the diaphysis can be neither retracted into a horizontal position, nor elevated further than $37^{\circ}$ (Figure 4). The asymmetry between the humeri is therefore reflected in their respective ranges of motion at the shoulder joint.

The diaphysis of the left radius is bent due to misaligned healing after a fracture (Senter and Juengst, 2016) (Figure 1.5, 1.6). The proximal end of the left ulna has been deformed due to an infection, such that there is a large lytic cavitation on the medial surface and a small bony growth on the medial edge of the articular surface (Senter and Juengst, 2016) (Figure 1.5, 1.7). Further deformation of the proximal portion of the ulna prevents the proximal articular surfaces of the left radius and ulna from achieving the degree of contact with the distal end of the humerus that is typically present in theropod skeletal specimens (Figure 1.7). Despite these pathological changes to the shapes of the bones of the left forelimb, the asymmetry between the elbow joint surfaces of the two forelimbs is not sufficient to result in large discrepancies in the ROM. However, the range of flexion of the left elbow can only be approximately determined, because the radial and ulnar condyles of the left humerus are less well-defined than those of the right humerus. It appears that each elbow can move through an arc of approximately $48^{\circ}$, and that each antebrachium can approach but not achieve flexion at a right angle to the humeral shaft. Accordingly, neither antebrachium can be extended so that it is in line with the humeral shaft (Figure 4). The right humerus has three bony tumors (Senter and Juengst, 2016; Figure 1.10), but these do not appear to have affected the elbow's ROM.

As with most other theropods (Sereno, 1993; Gishlick, 2001; Carpenter, 2002; Senter and Robins, 2005; Senter, 2006a, b), a lack of mutually opposed rolling surfaces at the distal ends of the radius and ulna prevents active supination and pronation, and the antebrachial bones are configured such that the palms face medially. This orientation of the palms is consistent with ichnological evidence from a trackway with manual impressions made by a theropod that was probably Dilophosaurus (Milner et al., 2009).

The ROM is smaller for the metacarpophalangeal joint of the thumb than for any of the other finger joints, except those immediately proximal to the unguals (Figure 4). In the right hand, a pathological condition associated with a deep pit on the palmar surface of phalanx $\mathrm{I}-1$ has caused considerable remodeling, such that the shape and dorsopalmar height of the phalanx are quite different between the two hands (Figure 2.7-10). There is a corresponding difference in ROM, which is $12^{\circ}$ greater in the right hand $\left(47^{\circ}\right)$ than the left $\left(35^{\circ}\right)$ (Figure 4.9, 4.14). The interphalangeal joint of the thumb exhibits a much larger ROM; the ungual is capable of moving through an arc of slightly over $90^{\circ}$ (Figure 4.9). In both hands, the asymmetric condyles of metacarpal I cause phalanx I-1 to lean away from the other digits-a condition that is plesiomorphic for Archosauria (Gauthier, 1984)-and to rotate about its long axis so that the tip of the ungual converges slightly toward the other digits during flexion but diverges away from them during hyperextension (Figure 5). An extensor fossa is present on the extensor (lateral) surface of the distal end of metacarpal I (Figure 3.7, 3.8); during hyperextension, phalanx I-1 approaches but does not enter the fossa.

In finger II the proximal phalanx is capable of extreme hyperextension, fitting snugly into the extensor fossa of metacarpal II during full hyperextension so that the proximal phalanx is at approximately a right angle to the metacarpal, with the proximal edge of the extensor fossa functioning as a bony stop (Figure 4.10, 4.16). The range of flexion at that joint is much smaller than the range of extension and is similar to that of the metacarpophalangeal joint of the thumb (Figure 4.9, 4.10, 4.14). Phalanx II-1 neither rotates about its long axis nor deviates toward or away from the other fingers during flexion (Figure 5), but rotates about its long axis during hyperextension such that the palmar surface of the finger is deflected $24^{\circ}$ toward the thumb (Figure 4.16). The ROM of the joint between phalanges II-1 and II-2 cannot be determined, because the distal end of phalanx II-1 is missing; the phalanx currently bears a fake, sculpted distal end (Figures 4.10,5). The ungual phalanx of digit II has approximately half the mobility of the ungual of the thumb and is only capable of moving through an arc of $45^{\circ}$ (Figure 4.11).

In finger III of the left hand, the proximal phalanx is capable of about the same degree of hyperextension seen in finger II, and the proximal edge 
of the extensor fossa again acts as a bony stop (Figure 4.12, 4.17). In contrast, the other phalanges are capable of much less hyperextension. All the phalanges of finger III are capable of more than $45^{\circ}$ of flexion (Figure 4.12). Finger III diverges away from the other fingers during flexion (Figure 5 ), and during hyperextension the proximal phalanx rotates about its long axis so that its palmar surface is deflected $22^{\circ}$ toward the thumb (Figure 4.17).

In finger III of the right hand, the preserved bones are strongly deformed. The metacarpal is only $89 \%$ the length of its counterpart in the left hand. The extensor end of its phalangeal articular surface is misshapen, and the raised rim that is present on the anterior edge of the extensor fossa of the corresponding metacarpal of the left hand is absent. The palmar part of the phalangeal articular surface is truncated (Figure 2.1-6) in such a way that the phalanx is permanently hyperextended (Figure 4.15). The proximal phalanx is also misshapen. Its proximal and distal articular surfaces are strongly slanted in comparison to their counterparts in the homologous phalanx of the left hand, so that the posterior edges of both the proximal and distal ends of the deformed phalanx extend further distally than the anterior edges (Figures $2.11-14,4.18)$. Nevertheless, the fit of the deformed phalanx with the metacarpal is snug throughout its ROM, indicating that the two bones were deformed together and not separately. As with the left hand, in full hyperextension the phalanx fits snugly into the extensor fossa of the metacarpal during full hyperextension so that it is at approximately a right angle to the metacarpal (Figure $4.15,4.18$ ). As a result of abnormal torsion about the long axis of the proximal phalanx, the palmar surface of this phalanx is turned $37^{\circ}$ toward the thumb during hyperextension (Figure 4.18), a much greater pollical deflection of the palmar surface than occurs in its counterpart in the left hand (Figure 4.17).

In the fourth finger of the left hand, the proximal phalanx is capable of only $6^{\circ}$ of hyperextension (Figure 4.13). However, this phalanx is capable of $67^{\circ}$ of flexion (Figure 4.13), a range of flexion comparable to those of the non-ungual phalanges of finger III (Figure 4.12). No other phalanges attributable to the fourth finger are preserved, and it is likely that this digit included only one phalanx even in life, because the distal surface lacks an articular facet for a second phalanx.

\section{Range of Motion: Dilophosaurus wetherilli (Intact Animal)}

In alligators, the ROM at the shoulder estimated from intact cadavers, in all dimensions, is similar to but slightly greater than that estimated using the bare-bones method (Hutson and Hutson, 2013). Because these animals represent one of the two major lineages of extant archosaurs, we can tentatively infer that the same may have been the case for Dilophosaurus wetherilli, another archosaur. This inference cannot be drawn with complete certainty, because the relationship between Dilophosaurus and extant archosaurs is distant. However, if it is correct, the ROM illustrated in Figure 4.5-7 for the shoulder joint with the undeformed humerus is a close approximation of the ROM in the shoulder of the live animal. The unusual range of shoulder motion illustrated in Figure 4.1-3 would then also be approximately accurate for the right shoulder of this particular individual, with its deformed right humerus.

If long-axis rotation of the humerus occurred, as it did inadvertently during elbow extension in the intact alligator cadavers used in this study, this movement would have influenced the positioning of the antebrachium. A small degree of long-axis rotation of the humerus occurs in walking alligators (Baier and Gatesy, 2013), and the avian tibiotarsus and tarsometatarsus regularly undergo long-axis rotation during locomotion (Kambic et al., 2014, 2017), further bolstering the possibility that longaxis rotation of the humerus took place in Dilophosaurus in some circumstances. Nothing about the bony articular surfaces that form the shoulder joint of Dilophosaurus contradicts the inference that at least some degree of long-axis rotation of the humerus was possible.

Values for maximum elbow flexion are approximately $20 \%$ greater for the ostrich, and approximately $50 \%$ greater for the alligator, when estimated from intact cadavers rather than using the bare-bones method (Hutson and Hutson, 2012; data in this paper). If bare-bones manipulations similarly underestimate the range of elbow flexion in extinct archosaurs, then the range of elbow flexion in live $D$. wetherilli was considerably greater than that illustrated in Figure 4.4 and 4.8, and possibly sufficient to allow the humerus and antebrachium to form an acute angle (Figure 7).

The articular cartilage of the alligator elbow also allows more extension than is found by the bare-bones method. Fujiwara et al. (2010) found that the articular cartilage of the elbow in alligators is shaped such that the olecranon process of the 


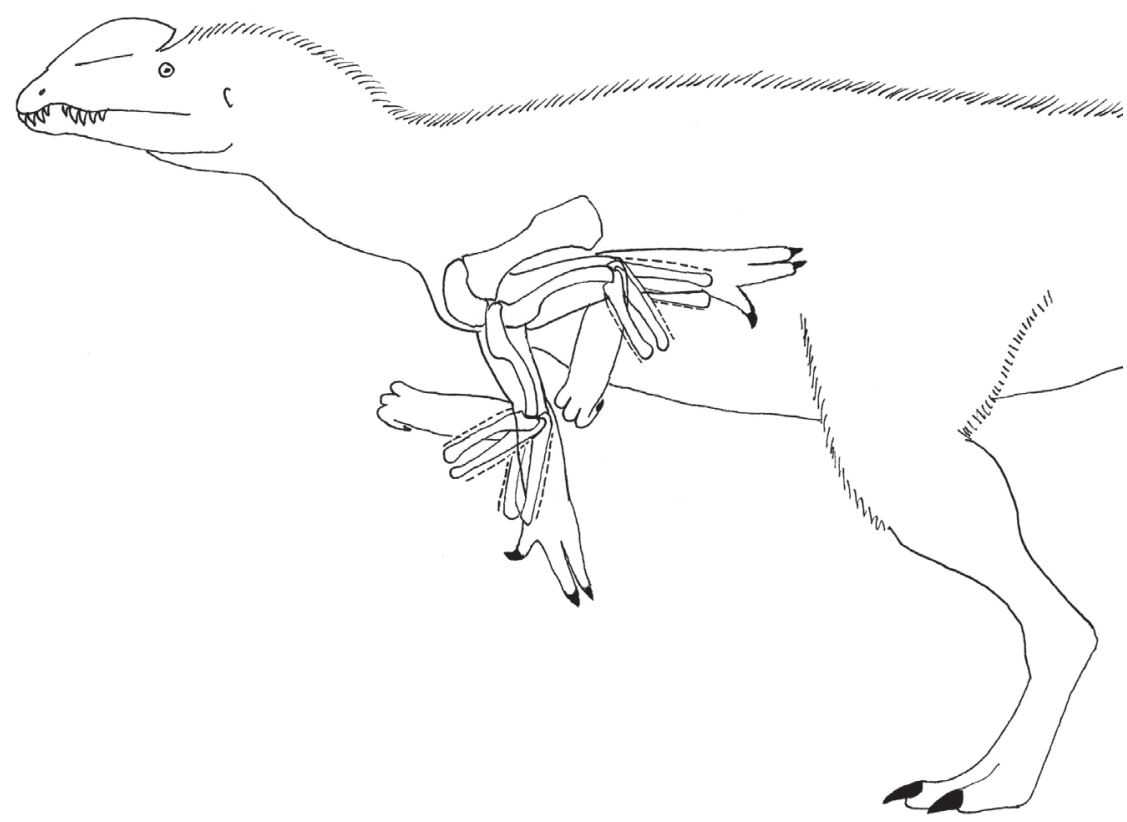

FIGURE 7. Reconstructed range of motion in the forelimb of Dilophosaurus wetherilli, with bare-bones range of elbow motion indicated by broken lines, showing that the influence of soft tissues allows for more elbow flexion and extension in the fully-fleshed animal than the bony articular surfaces at the elbow indicate.

ulna fits into the olecranon fossa of the humerus during extension, as is also the case in birds. It is therefore plausible that full elbow extension in live Dilophosaurus was closer to $180^{\circ}$ than suggested by the bare-bones method.

In extant archosaurs, active pronation by crossing the radius over the ulna is not possible. A lateral expansion of the proximal ulna prevents passive radioulnar mobility in ostriches and other extant birds (Hutson and Hutson, 2015b), and a corresponding expansion which would presumably have had a similarly restrictive effect is present in the Dromaeosauridae (Senter, 2006b; Hutson and Hutson, 2015b), Troodontidae (personal observation by P.S., 2010), and Oviraptorosauria (personal observation by P.S., 2010). In contrast, soft and bony anatomy allow a small degree of passive radioulnar mobility in the alligator (Hutson and Hutson, 2015b). The lateral expansion of the proximal ulna that prevents passive radioulnar mobility in birds and the other aforementioned pennaraptoran theropods is absent in $D$. wetherilli. It is therefore plausible that a small degree of passive radioulnar mobility was possible in $D$. wetherilli, as in alligators.

The ROM at the wrist of $D$. wetherilli cannot be estimated with any reasonable degree of precision, because only one carpal bone was available for this study. However, previous studies have determined that wrist ROM in the plane of the manus is much greater in theropods in which the distal carpal block (distal carpals $1+2$ ) is semilunate than in theropods in which it is not (Gishlick, 2001; Carpenter, 2002; Senter, 2006b). The lack of a semilunate shape in the distal carpal block of $D$. wetherilli therefore suggests a smaller range of wrist motion in the plane of the manus than is present in theropods with semilunate carpals.

In the alligator, ranges of motion for intact cadavers are slightly lower for the manual interphalangeal joints, and slightly higher for the metacarpophalangeal joints, than those found using the bare-bones method (Hutson and Hutson, 2015a). In both cases, however, the difference between the ROM estimates from the two methods is small. If the same was the case for extinct archosaurs, it is plausible that the ROM of the fingers in live $D$. wetherilli was similar to that illustrated in Figures 4 and 5. In the emu, the ROM of the joints of the intact foot is lower than that found using the barebones method, and the difference is pronounced at most joints (an average difference of $16^{\circ}$ for extension and $24^{\circ}$ for flexion) (White et al., 2016, table 2 ). However, we suggest caution in applying the emu foot results to the hand of $D$. wetherilli, because of the possibility that soft-tissue constraints on ROM observed in the foot of one biped may be inapplicable to the hand of another.

Intraspecific variation exists in the ROM at the elbow of the American alligator, but values for the 
specimens examined in this study differ only slightly (Table 1). If this pattern holds true for other joints and other archosaur taxa, then forelimb ROM results for the holotype of $D$. wetherilli can likely be regarded as typical for the species as a whole.

\section{Forelimb Function in Dilophosaurus wetherilli}

Senter (2006b) presented a list of hypotheses relating to actions a theropod could potentially perform with its forelimbs. Each hypothesis was accompanied by a list of predictions regarding morphological features and minimum ROM that would be observed if the forelimb were suited to the action in question. The list will not be repeated here but can be used as a convenient template for assessing forelimb function in $D$. wetherilli. The morphology and ROM in the forelimbs of $D$. wetherilli falsify the hypotheses that it was able to use its forelimbs to perform scratch-digging; to perform hook-and-pull digging; to hold an object between opposing fingertips of one hand; to hook or seize an object that was positioned anywhere but directly beneath, or a short distance lateral or anterior to, the ventral surface of the chest; to perform a display that involved swinging the arms in a large, transverse arc; to maintain balance by extending the forelimbs laterally; to scratch any bodily surface other than the chest, belly, or distal half of the opposing forelimb; or to probe small crevices, as in the extant aye-aye (Daubentonia madagascariensis).

The morphology and ROM in the forelimbs of $D$. wetherilli are consistent with the hypotheses that it was able to use its forelimbs to grip and maintain a two-handed hold upon an object, with the palms, fingers, and/or claws as the primary agents of prehension; to grip and hold an object with one hand, provided that the object was only a few cm in diameter; to hook or seize an object that was directly beneath, or a short distance anterior or lateral to, the ventral surface of the chest; to bring an object to the mouth; to perform a display that involved swinging the arms in a parasagittal arc along the sides of the ribcage; to scratch the chest, belly, or distal half of the opposing forelimb; or to clutch an object to the chest.

\section{DISCUSSION}

\section{Comparison with Welles' Results}

Our conclusions regarding the forelimb mobility of $D$. wetherilli are similar in some ways to those reported by Welles (1984) but differ from them in others. Welles stated that the humerus could be retracted to a position subparallel with the scapula and protracted no further than the vertical, which matches our results (Figure 4.5). However, he also stated that this arc of motion was about $135^{\circ}$, whereas we measured it as $85^{\circ}$ (Figure 4.5). Because Welles (1984) did not describe the method that he used to measure the ROM, we cannot assess the reasons for this discrepancy between his results and ours. Welles (1984) stated that the elbow could not be flexed beyond a right angle and could be extended to about $150^{\circ}$. This agrees with our bare-bones ROM estimates (Figure 4.4, 4.8), although the experiments with ostriches and alligators mentioned above indicate that the elbow's ROM in the intact animal would have been greater. Welles (1984) stated that "the outer rotation [i.e. torsion] of the distal end of the humerus would cause the forearm to project anterolaterally." However, that applies only to the pathologically-deformed right humerus and not to the healthy left humerus (Senter and Juengst, 2016). Our results for ROM in the hand of $D$. wetherilli (Figures 4.9-13, 5) resemble those reported and illustrated by Welles (1984), except that our measurement of the range of hyperextension of phalanx IV-1 is much lower than that suggested by his illustration.

\section{The Influence of Pathology, Individual Variation, and Soft Tissues}

Our results show that it is important to take pathology into consideration when reconstructing ROM in extinct animals. In the holotype of Dilophosaurus wetherilli the petrified pectoral limbs are peppered with a plethora of paleopathological peculiarities that point to a plenitude of potentially painful problems that plagued the poor prehistoric predator. These conditions created morphological asymmetry between the two forelimbs, and a corresponding set of discrepancies in their inferred ranges of motion. More specifically, pathological conditions significantly altered the ROM in the right shoulder and right third finger of the $D$. wetherilli holotype. ROM estimates for a forelimb with pathologically-altered joint surfaces therefore may not match those for a non-pathological forelimb in a conspecific individual.

Our results also show that individual variation exists in ROM, at least in the elbow of the American alligator. However, that variation is small, with a difference of only $16^{\circ}$ between the maximum and minimum elbow flexion in our sample (Table 1). For reconstructing the kinematic capabilities of extinct animals, it would be useful to determine to what 
extent the magnitude of intraspecific variation differs across joints and across taxa. Future studies will be necessary to make those determinations.

Our results and those of Hutson and Hutson (2012) show that the archosaur elbow is capable of greater flexion than bare-bones manipulation would suggest. This explains the otherwise-enigmatic finding that articulated saurischian skeletons often have their elbows flexed to a greater degree than bare-bones manipulation suggests is possible. For example, in basal, bipedal sauropodomorphs, bare-bones manipulations indicate that the elbow cannot flex much beyond a right angle (Bonnan and Senter, 2007; Mallison, 2010), but the elbow is flexed at a more acute angle in some articulated skeletons (Senter and Robins, 2015). Likewise, bare-bones manipulation suggests that dromaeosaurid elbows can flex no further than $50^{\circ}$ (Senter, 2006b), but the elbow is flexed at a more acute angle in some articulated skeletons of dromaeosaurids and other Mesozoic paravians (Senter and Robins, 2015).

\section{Comparison with Other Archosaurs}

The range of elbow flexion and extension, as estimated from bare-bones manipulation, is similar among Dilophosaurus, other non-coelurosaurian theropods (Carpenter, 2002; Senter and Robins, 2005), basal sauropodomorphs (Bonnan and Senter, 2007; Langer et al., 2007), and the basal, bipedal ceratopsian Psittacosaurus (Senter, 2007). The elbow is capable of much greater flexion in coelurosaurs (Gishlick, 2001; Carpenter, 2002; Senter, 2006b) and in the quadrupedal ceratopsian Leptoceratops (Senter, 2007). It therefore appears that the limited range of elbow motion of Dilophosaurus is the plesiomorphic condition in Dinosauria, and that the greater ability to flex the elbow in Coelurosauria and Ceratopsia is a derived condition.

Likewise, the limited range of motion of the shoulder of Dilophosaurus appears to be plesiomorphic for Dinosauria. Dilophosaurus shares the inability to protract the humerus beyond a sub-vertical position with other non-coelurosaurian theropods (Carpenter, 2002; Senter and Robins, 2005), sauropodomorphs (Bonnan and Senter, 2007; Langer et al., 2007), and basal ceratopsians (Senter, 2007). Dilophosaurus shares the inability to laterally elevate the humerus to a horizontal position with other non-coelurosaurian theropods (Carpenter, 2002; Senter and Robins, 2005), sauropodomorphs (Bonnan and Senter, 2007; Langer et al., 2007), and Psittacosaurus (Senter, 2007).
This indicates that the greater ability to protract the humerus in Dromaeosauridae (Senter, 2006b), as well as the greater ability to elevate the humerus in Paraves (Senter, 2006b), Ornithomimosauria (Senter, 2006c), and quadrupedal ceratopsians (Senter, 2007), represent derived conditions. The increases in maximal humeral protraction and elevation in those taxa were evidently due to an extension of the glenoid cavity onto the lateral surface of the scapula and coracoid (Senter, 2006b, 2006c, 2007).

Alligators and other quadrupedal, non-dinosaurian archosaurs retain the plesiomorphic reptilian condition in which the glenoid cavity faces laterally, allowing the humerus to be laterally elevated to a horizontal position. That capability is an important one in an animal that uses retraction of the humerus about a vertical axis to propel itself (Baier and Gatesy, 2013). Because such motion is unimportant for bipedal locomotion, bipedal posture in basal dinosaurs allowed the glenoid to be reoriented so that it faced ventrally (Senter, 2006c) without compromising locomotion. The reorientation of the glenoid in Dinosauria shifted the ROM of the humerus, so that humeral motion in the plane of the glenoid's long axis was now parasagittal instead of transverse. This may have been advantageous in making it easier to seize prey beneath the predator's torso. The secondary re-extension of the glenoid cavity in Ornithomimosauria and Paraves, allowing the humerus to be laterally elevated, suggests that such a motion probably had some functional importance in those animals. That importance may plausibly have been related to display involving forelimb feathers, a feature present in Ornithomimosauria (Zelenitsky et al., 2012) and Paraves (Xu et al., 2003; Hu et al., 2009) but unknown in basal coelurosaurs (Chen et al., 1998; $\mathrm{Ji}$ et al., 2007) and in non-coelurosaurian theropods such as Dilophosaurus. The lateral extension of the glenoid is retained in the ostrich (personal observation by P.S., 2007), which uses forelimb elevation in display (Davies, 2002). It is lost in kiwis (McGowan, 1982) and the emu (Maxwell and Larsson, 2007), which do not use the forelimbs in display (Davies, 2002).

The palms face medially in Dilophosaurus, because the distal end of the radius is not crossed over the distal ulna, and a lack of suitable articular surfaces prevented the radius from being actively rotated into a pronated position. Dilophosaurus shares that condition with other theropods (Gishlick, 2001; Carpenter, 2002; Senter and Robins, 2005; Senter, 2006b) and with bipedal ornithischi- 
ans such as ornithopods (Senter, 2012) and basal ceratopsians (Senter, 2007). Medial orientation of the palms is therefore the plesiomorphic condition for Dinosauria. The distal end of the radius is strongly crossed over the distal ulna in derived sauropods (Bonnan, 2003), is crossed over the distal ulna to a lesser degree in basal sauropods such as Melanorosaurus (Bonnan and Yates, 2007), and is only slightly displaced toward the anterior side of the distal ulna in basal sauropodomorphs such as Plateosaurus, Massospondylus, and Saturnalia (Bonnan and Senter, 2007; Langer et al., 2007). This decrease in the degree of radial crossover in increasingly basal sauropodomorphs is consistent with an inferred lack of radial crossover, due to the geometry of the forelimb skeleton, in the common ancestor of Saurischia and of Dinosauria.

Previous work shows that the extensor fossae of extant archosaur metacarpals are covered in a thin film of articular cartilage, but that no other soft tissue impedes entry of the proximal phalanx into the extensor fossa during hyperextension (Hutson and Hutson, 2015a). A similar situation is present in the avian foot (White et al., 2016). The proximal phalanges of alligators fit snugly into the extensor fossae of the metacarpals during hyperextension. This is important for quadrupedal locomotion in alligators, and the same appears to have been the case in extinct quadrupedal archosaurs (Hutson and Hutson, 2015a). At least some of the proximal phalanges fit snugly into the extensor fossae of the metacarpals during hyperextension in $D$. wetherilli and some other non-coelurosaurian theropods such as Megapnosaurus rhodesiensis (Galton, 1971) and Acrocanthosaurus atokensis (Senter and Robins, 2005). In such cases, the articular surface on the distal end of the metacarpal visibly continues onto the distal wall of the extensor fossa. However, that is not the case in other theropods, including Allosaurus fragilis and every coelurosaur for which manual ROM has been investigated. In those taxa, the proximal phalanges do not appear to have entered the extensor fossae of the metacarpals (Osmólska and Roniewicz, 1969; Osmólska et al., 1972; Nicholls and Russell, 1985; Gishlick, 2001; Carpenter, 2002; Kobayashi and Barsbold, 2005; Senter, 2005, 2006b; Senter and Parrish, 2005). The extensor fossae of coelurosaurs are reduced, shallow, and often barely discernible, as is expected in animals in which those fossae do not receive the proximal phalanges.

Another forelimb trait that differs between Dilophosaurus and coelurosaurs is radioulnar mobility. Passive radioulnar mobility is prevented in extant birds by proximal and distal forearm ligaments and by a lateral expansion of the proximal ulna that functions as a bony stop (Hutson and Hutson, 2015b). As previously mentioned, a similar lateral expansion of the proximal ulna is found in the coelurosaurs that are most closely related to birds: Dromaeosauridae, Troodontidae, and Oviraptorosauria. Such a lateral ulnar expansion is absent in at least some coelurosaurian taxa that are less closely related to birds: Therizinosauroidea (Zanno, 2006), Ornithomimidae (personal observation by P.S., 2008), and Ornitholestes (Senter, 2006a). The expansion is also absent in Dilophosaurus and other non-coelurosaurian theropods such as Acrocanthosaurus (Senter and Robins, 2005), Torvosaurus (personal observation by P.S., 2006), and Herrerasaurus (Sereno, 1993). A small degree of passive radioulnar mobility was therefore probably present in Dilophosaurus and other theropod taxa not closely related to birds, as is the case in extant alligators (Hutson and Hutson, 2015b).

The likelihood that any mobility between the radius and ulna that existed in $D$. wetherilli was passive in nature points to a more general issue regarding inferred ranges of motion in fossil vertebrates. Experiments on modern cadavers (Hutson and Hutson,, 2012; White et al., 2016; this study) generate correction factors that can be applied to bare-bones estimates of ROM for particular joints, but the corrected estimates strictly pertain to a dead rather than a living specimen of the extinct taxon in question. In other words, the conclusions about joint motion presented in this study for an "intact" $D$. wetherilli represent inferences about the positions in which the joints of a $D$. wetherilli cadaver could hypothetically be placed by a timetravelling experimenter without damaging the ligaments, muscles and other soft tissues associated with the joint. However, there is no guarantee that the full cadaveric ROM that can be justifiably inferred for any given joint in an extinct vertebrate was ever exploited by the animal in the course of its normal behavior. Some joint positions may have been achievable only through the application of external force to the joint in question, and may therefore never have been utilized by the animal. Inferred (cadaveric) ranges of motion, which may be either larger or smaller than raw bare-bones estimates depending on the joint, should therefore be regarded as placing outer limits on the animal's behavioral repertoire. Movements that appear impossible based on inferred ranges of motion can be ruled out with relatively high confidence, but 
movements that appear possible may or may not have ever actually been performed. For example, Baier and Gatesy (2013) found that walking alligators use much less than the total ROM of which the alligator shoulder (Hutson and Hutson, 2013) and elbow (Table 1) are capable.

\section{Functional and Behavioral Inferences}

Like other theropods, $D$. wetherilli was bipedal. However, ichnological evidence indicates that when $D$. wetherilli did place its hands on the ground, contact involved the posterior edge and not the palmar surface of the hand (Milner et al., 2009), presumably due to medially-facing palms and inability to actively pronate the manus. Finger hyperextension was therefore unimportant for locomotion and stationary body support in $D$. wetherilli, as in other theropods. Its functional significance may have lain in preventing the violent struggles of prey from causing finger dislocation, because it allowed a great degree of passive finger motion.

The correction factors provided by recent studies on the influence of soft-tissue on ROM are important in estimating ROM in extinct animals. Previous studies on theropod forelimb ROM could not include such correction factors, because the experimental work needed to generate them had not yet been performed. Therefore, results from older studies of forelimb ROM in extinct archosaurs should be adjusted using the appropriate correction factors when used as a basis for functional inferences.

With this logic in mind, the ROM of the forelimbs can be said to place important limits on prey size and predatory behavior in Dilophosaurus wetherilli. The limited ROM at the shoulder, combined with the shortness of the forelimbs, prevented the animal from manually seizing prey that was located anywhere but beneath the predator's chest or the base of its neck, or immediately lateral to the space beneath its chest. At best, manual capture would only have been an option when attacking prey small enough to fit beneath the predator's chest, or larger prey that had been forced down with the predator's mouth. In addition, the great head and neck length of $D$. wetherilli (Welles, 1984) would have enabled the snout to extend much further forward than the hands could reach, making the mouth much more likely than the hands to have made first contact with prey. A previous study made similar inferences regarding predatory behavior in Acrocanthosaurus atokensis, whose range of forelimb motion resembles that of D. wetherilli (Senter and Robins, 2005). In contrast, theropods with a dorsolateral extension of the glenoid, such as members of Dromaeosauridae, had a greater range of shoulder motion and could have seized prey considerably further forward than the predator's chest (Senter, 2006b). The shape of the glenoid and humeral head, along with the shortness of the forelimb, is similar among $D$. wetherilli, A. atokensis, and basal theropods such as Herrerasaurus ischigualastensis (Sereno, 1993). It is therefore plausible that the above limitations on the use of the forelimb in predation that were present in $D$. wetherilli and $A$. atokensis represent the ancestral condition in the Theropoda.

\section{ACKNOWLEDGMENTS}

Several individuals deserve thanks for their help with this study, Part 17 of the Dinosaur Forelimb Project. L. Claessens made four of the intact alligators available to C. Sullivan, and S. Wu helped make the $\mathrm{x}$-ray radiographs. The work of $\mathrm{C}$. Sullivan was financially supported by the Department of Organismic and Evolutionary Biology of Harvard University and a Chapman Fellowship. P. Holroyd, and K. Padian provided access to Dilophosaurus at the University of California Museum of Paleontology. J. Hutson and anonymous reviewers provided helpful input on earlier versions of this paper.

\section{REFERENCES}

Baier, D.B. and Gatesy, S.M. 2013. Three-dimensional skeletal kinematics of the shoulder girdle and forelimb in walking Alligator. Journal of Anatomy, 223:462-473. https://doi.org/10.1111/ joa.12102

Bonnan, M.F. 2003. The evolution of manus shape in sauropod dinosaurs: implications for functional morphology, forelimb orientation, and phylogeny. Journal of Vertebrate Paleontology, 23:595-613. https://doi.org/10.1671/a1108 
Bonnan, M.F. and Senter, P. 2007. Were the basal sauropodomorph dinosaurs Plateosaurus and Massospondylus habitual quadrupeds? Special Papers in Palaeontology, 77:139-155.

Bonnan, M.F. and Yates, A.M. 2007. A new description of the forelimb of the basal sauropodomorph Melanorosaurus: Implications for the evolution of pronation, manus shape, and quadrupedalism in sauropod dinosaurs. Special Papers in Palaeontology, 77:157-168.

Botelho, J.F., Osaa-Fuentes, L., Soto-Acuña, S., Smith-Paredes, D., Nuñez-Léon, D., SalinasSaavedra, M., Ruiz-Flores, M., and Vargas, A.O. 2014. New developmental evidence clarifies the evolution of wrist bones in the dinosaur-bird transition. PLoS Biology, 12(9):e1001957. https://doi.org/10.1371/journal.pbio.1001957

Carpenter, K. 2002. Forelimb biomechanics of nonavian theropod dinosaurs in predation. Senckenbergiana Lethaea, 82:59-76. https://doi.org/10.1007/bf03043773

Chen, P., Dong, Z., and Zhen, S. 1998. An exceptionally well-preserved theropod dinosaur from the Yixian Formation of China. Nature, 391:147-152. https://doi.org/10.1038/34356

Colbert, E.H. 1989. The Triassic dinosaur Coelophysis. Museum of Northern Arizona Bulletin, 57:1-160.

Davies, S.J.J.F. 2002. Ratites and Tinamous. Oxford University Press, Oxford.

Fujiwara, S., Taru, H., and Suzuki, D. 2010. Shape and articular surface of crocodilian (Archosauria) elbow joints and its relevance to sauropsids. Journal of Morphology, 271:883896. https://doi.org/10.1002/jmor.10846

Galton, P.M. 1971. Manus movements of the coelurosaurian dinosaur Syntarsus and opposability of the theropod hallux. Arnoldia (Rhodesia), 15:1-8.

Gauthier, J.A. 1984. A Cladistic Analysis of the Higher Systematic Categories of the Diapsida. Unpublished PhD Thesis, University of California, Berkeley, California, USA.

Gishlick, A.D. 2001. The function of the manus and forelimb of Deinonychus antirrhopus and its importance for the origin of avian flight, p. 301-318. In Gauthier, J. and Gall, L.F. (eds.), New Perspectives on the Origin and Early Evolution of Birds. Yale Peabody Museum, New Haven.

Holliday, C.M., Ridgely, R.C., Sedlmayr, J.C., and Witmer, L.M. 2010. Cartilaginous epiphyses in extant archosaurs and their implications for reconstructing limb function in dinosaurs. PLoS ONE, 5(9):e13120. https://doi.org/10.1371/journal.pone.0013120

$\mathrm{Hu}$, D., Hou, L., Zhang, L., and Xu, X. 2009. A pre-Archaeopteryx troodontid theropod from China with long feathers on the metatarsus. Nature, 461:460-463. https://doi.org/10.1038/ nature08322

Hutson, J.D. and Hutson, K.N. 2012. A test of the validity of range of motion studies of fossil archosaur elbow mobility using repeated-measures analysis and the extant phylogenetic bracket. Journal of Experimental Biology, 215:2030-2038. https://doi.org/10.1242/jeb.069567

Hutson, J.D. and Hutson, K.N. 2013. Using the American alligator and a repeated-measures design to place constraints on in vivo shoulder joint range of motion in dinosaurs and other fossil archosaurs. Journal of Experimental Biology, 216:275-284. https://doi.org/10.1242/ jeb.074229

Hutson, J.D. and Hutson, K.N. 2014. A repeated-measures analysis of the effects of soft tissues on wrist range of motion in the extant phylogenetic bracket of dinosaurs: implications for the functional origins of an automatic wrist-folding mechanism in Crocodilia. Anatomical Record, 297:1228-1249. https://doi.org/10.1002/ar.22903

Hutson, J.D. and Hutson, K.N. 2015a. Inferring the prevalence and function of finger hyperextension in Archosauria from finger-joint range of motion in the American alligator. Journal of Zoology (London), 296:189-199. https://doi.org/10.1111/jzo.12232

Hutson, J.D. and Hutson, K.N. 2015b. An examination of forearm bone mobility in Alligator mississippiensis (Daudin, 1802) and Struthio camelus Linnaeus, 1758 reveals that Archaeopteryx and dromaeosaurs shared an adaptation for gliding and/or flapping. Geodiversitas, 37:325-344. https://doi.org/10.5252/g2015n3a3

Ji, S., Ji, Q., Lü, J., and Yuan, C. 2007. A new giant compsognathid dinosaur with long filamentous integuments from the Lower Cretaceous of Northeastern China. Acta Geologica Sinica, 81:8-15.

Kambic, R.E., Roberts, T.J., and Gatesy, S.M. 2014. Long-axis rotation: a missing degree of freedom in avian bipedal locomotion. Journal of Experimental Biology, 217:2770-2782. https:/ /doi.org/10.1242/jeb.101428

Kambic, R.E., Roberts, T.J., and Gatesy, S.M. 2017. 3-D range of motion envelopes reveal interacting degrees of freedom in avian hind limb joints. Journal of Anatomy, 231:906-920. https://doi.org/10.1111/joa.12680 
Kobayashi, K. and Barsbold, R. 2005. Anatomy of Harpymimus okaldnikovi Barsbold and Perle 1984 (Dinosauria; Theropoda) of Mongolia, p. 97-126. In Carpenter, K. (ed.), The Carnivorous Dinosaurs. Indiana University Press, Bloomington.

Langer, M.C., França, M.A.G., and Gabriel S. 2007. The pectoral girdle and forelimb anatomy of the stem-sauropodomorph Saturnalia tupiniquim (Upper Triassic, Brazil). Special Papers in Palaeontology, 77:113-137.

Mallison, H. 2010. The digital Plateosaurus II: an assessment of the range of motion of the limbs and vertebral column and of previous reconstructions using a digital skeletal mount. Acta Palaeontologica Polonica, 55:433-458. https://doi.org/10.4202/app.2009.0075

Maxwell, E.E. and Larsson, H.C.E. 2007. Osteology and myology of the wing of the emu (Dromaius novaehollandiae), and its bearing on the evolution of vestigial structures. Journal of Morphology, 268:423-441. https://doi.org/10.1002/jmor.10527

McGowan, C. 1982. The wing musculature of the Brown Kiwi Apteryx australis mantelli and its bearing on ratite affinities. Journal of Zoology (London), 197:173-219. https://doi.org/10.1111/ jzo.1982.197.2.173

Milner, A.R.C., Harris, J.D., Lockley, M.G., Kirkland, J.I., and Matthews, N.A. 2009. Bird-like anatomy, posture, and behavior revealed by an Early Jurassic theropod dinosaur resting trace. PLoS ONE, 4(3):e4591. https://doi.org/10.1371/journal.pone.0004591

Nicholls, E.L. and Russell, A.P. 1985. Structure and function of the pectoral girdle and forelimb of Struthiomimus altus (Theropoda: Ornithomimidae). Palaeontology, 28:643-677.

Osmólska, H. and Roniewicz. E. 1969. Deinocheiridae, a new family of theropod dinosaurs. Palaeontologia Polonica, 27:5-19.

Osmólska, H., Roniewicz, E., and Barsbold, R. 1972. A new dinosaur, Gallimimus bullatus n. gen., n. sp. (Ornithomimidae) from the Upper Cretaceous of Mongolia. Palaeontologia Polonica, 27:103-143.

Raath, M.A. 1969. A new coelurosaurian dinosaur from the Forest Sandstone of Rhodesia. Arnoldia (Rhodesia), 4:1-25.

Senter, P. 2005. Function in the stunted forelimbs of Mononykus olecranus (Theropoda), a dinosaurian anteater. Paleobiology, 31:373-381. https://doi.org/10.1666/00948373(2005)031[0373:fitsfo]2.0.co;2

Senter, P. 2006a. Forelimb function in Ornitholestes hermanni Osborn (Dinosauria, Theropoda). Palaeontology, 49:1029-1034. https://doi.org/10.1111/j.1475-4983.2006.00585.x

Senter, P. 2006b. Comparison of forelimb function between Deinonychus and Bambiraptor (Theropoda: Dromaeosauridae). Journal of Vertebrate Paleontology, 26:897-906. https:// doi.org/10.1671/0272-4634(2006)26[897:coffbd]2.0.co;2

Senter, P. 2006c. Scapular orientation in theropods and basal birds, and the origin of flapping flight. Acta Palaeontologica Polonica, 51:305-313.

Senter, P. 2007. Analysis of forelimb function in basal ceratopsians. Journal of Zoology (London), 273:305-314. https://doi.org/10.1111/j.1469-7998.2007.00329.x

Senter, P. 2012. Forearm orientation in Hadrosauridae (Dinosauria: Ornithopoda) and implications for museum mounts. Palaeontologia Electronica, 15.3.30A:1-10. https://doi.org/ 10.26879/330 palaeo-electronica.org/content/2012-issue-3-articles/324-hadrosaurid-forearm

Senter, P. and Juengst, S.L. 2016. Record-breaking pain: the largest number and variety of forelimb maladies in a theropod dinosaur. PLoS ONE, 11(2):30149140. https://doi.org/ 10.1371/journal.pone.0149140

Senter, P. and Parrish, J.M. 2005. Functional analysis of the hands of the theropod dinosaur Chirostenotes pergracilis: Evidence for an unusual paleoecological role. PaleoBios, 25(2):919.

Senter, P. and Parrish, J.M. 2006. Forelimb function in the theropod dinosaur Carnotaurus sastrei, and its behavioral implications. PaleoBios, 26(3):7-17.

Senter, P. and Robins, J.H. 2005. Range of motion in the forelimb of the theropod dinosaur Acrocanthosaurus atokensis, and implications for predatory behaviour. Journal of Zoology (London), 266:307-318. https://doi.org/10.1017/s0952836905006989

Senter, P. and Robins, J.H. 2015. Resting orientations of dinosaur scapulae and forelimbs: a numerical analysis, with implications for reconstructions and museum mounts. PLoS ONE, 10(12):e0144036. https://doi.org/10.1371/journal.pone.0144036

Sereno, P.C. 1993. Pectoral girdle and forelimb of the basal theropod Herrerasaurus ischigualastensis. Journal of Vertebrate Paleontology, 13:425-450. https://doi.org/10.1080/ 02724634.1994.10011524 
Smith, N.D., Makovicky, P.J., Hammer, W.R., and Currie, P.J. 2007. Osteology of Cryolophosaurus ellioti (Dinosauria: Theropoda) from the Early Jurassic of Antarctica and implications for early theropod evolution. Zoological Journal of the Linnean Society, 151:377421. https://doi.org/10.1111/j.1096-3642.2007.00325.x

Tsai, H.P. and Holliday, C.M. 2015. Articular soft tissue anatomy of the archosaur hip joint: Structural homology and functional implications. Journal of Morphology, 276:601-630. https:// doi.org/10.1002/jmor.20360

Welles, S.P. 1954. New Jurassic dinosaur from the Kayenta Formation of Arizona. Bulletin of the Geological Society of America, 65:591-598. https://doi.org/10.1130/00167606(1954)65[591:njdftk]2.0.co;2

Welles, S.P. 1970. Dilophosaurus (Reptilia: Saurischia), a new name for a dinosaur. Journal of Paleontology, 44:989.

Welles, S.P. 1984. Dilophosaurus wetherilli (Dinosauria, Theropoda). Osteology and comparisons. Palaeontographica Abteilung A, 185:85-180.

White, M.A., Bell, P.R., Cook, A.G., Barnes, D.G., Tischler, T.R., Bassam, B.J., and Elliott, D.A. 2015. Forearm range of motion in Australovenator wintonensis (Theropoda, Megaraptoridae). PLoS ONE, 10(9):e0137709. https://doi.org/10.1371/journal.pone.0137709

White, M.A., Cook, A.G., Klinkhamer, A.J., and Elliott, D.A. 2016. The pes of Australovenator wintonensis (Theropoda: Megaraptoridae): analysis of the pedal range of motion and biological restoration. PeerJ, 4:e2312. https://doi.org/10.7717/peerj.2312

Witmer, L.M. 1995. The Extant Phylogenetic Bracket and the importance of reconstructing soft tissues in fossils, p. 19-33. In Thomason, J.J. (ed.), Functional Morphology in Vertebrate Paleontology. Cambridge University Press, New York.

Xu, X., Zhou, Z., Wang, X., Kuang, X., Zhang, F., and Du, X. 2003. Four-winged dinosaurs from China. Nature, 421:335-340. https://doi.org/10.1038/nature01342

Zanno, L.E. 2006. The pectoral girdle and forelimb of the primitive therizinosauroid Falcarius utahensis (Theropoda, Maniraptora): analyzing evolutionary trends within Therizinosauroidea. Journal of Vertebrate Paleontology, 26:636-650. https://doi.org/10.1671/ 0272-4634(2006)26[636:tpgafo]2.0.co;2

Zelenitsky, D.K., Therrien, F., Erickson, G.M., DeBuhr, C.L., Kobayashi, Y., Eberth, D.A., and Hadfield, F. 2012. Feathered non-avian dinosaurs from North America provide insight into wing origins. Science, 388:510-514. https://doi.org/10.1126/science.1225376 